\title{
Detection of remaining Plasmodium DNA and gametocytes during follow up after curative malaria treatment among returned travellers in Norway
}

\author{
Christel Gill Haanshuus $^{1 *}$ (ID and Kristine Mørch ${ }^{1,2}$
}

\begin{abstract}
Background: PCR can be positive weeks after effective malaria treatment, potentially leading to over diagnose of recrudescence and re-infections. The DNA detected by PCR post-treatment might stem from residuals of destroyed asexual parasites, or from live gametocytes. The objective of this clinical observational study was to describe the presence of positive PCR for Plasmodium falciparum and Plasmodium vivax in follow-up samples post-treatment from returned travellers, and the proportion of positive PCR due to gametocytes.

Methods: Whole blood was collected during hospitalization and outpatient routine follow-up from 13 patients with imported malaria. DNA was extracted applying QIAamp DNA Blood Mini Kit, while mRNA was collected and extracted applying PAXgene Blood RNA Tubes and Kit. All DNA samples $(N=25)$ were analysed with a genus-specific cytb real-time SYBR PCR, and P. falciparum DNA samples $(N=22)$ were also analysed with a falciparum-specific varATS real-time TaqMan PCR. All the mRNA samples $(N=18)$ were analysed with both a genus-specific $18 S$ rRNA RT-PCR and a gametocyte-specific Pfs25 (P. falciparum)/Pvs25 (P. vivax) RT-PCR.
\end{abstract}

Results: Latest samples were collected at day $1(n=2)$ and from day 11-54 $(n=11)$ after treatment. Genus DNA cytb PCR was positive up to 49 days after effective treatment, and 185 rRNA transcripts from active $P$. falciparum parasites were detectable for at least 11 days. Gametocyte-specific mRNA was detected at latest only two days after treatment. Among six patients with late positive PCR for P. falciparum, four had high parasitaemia at admittance (6-30\%), while two had parasitaemia $<2 \%$. Late detection of $P$. vivax was not found by any of the PCR methods.

Conclusions: DNA-based PCR can be positive up to at least seven weeks after curative malaria treatment, potentially leading to over-diagnose of recrudescence and re-infections. Based on the observations in this study, it is unclear if the DNA origins from residuals of destroyed parasites or live gametocytes, warranting further investigations.

Keywords: Malaria, Plasmodium falciparum, Plasmodium vivax, Gametocyte, PCR, RT-PCR, mRNA, DNA, Travellers, Posttreatment

\footnotetext{
*Correspondence: christel.gill.haanshuus@helse-bergen.no

${ }^{1}$ Norwegian National Advisory Unit On Tropical Infectious Diseases, Unit

for Infectious Diseases, Department of Medicine, Haukeland University Hospital, Bergen, Norway

Full list of author information is available at the end of the article
}

\section{Background}

Polymerase chain reaction (PCR) detecting Plasmodium DNA is the most sensitive method for diagnosing malaria, and used as reference method for routine diagnostics and in epidemiological surveys. However, PCR can be positive weeks after effective malaria treatment, potentially leading to over-diagnose of recrudescence and

(c) The Author(s) 2020. This article is licensed under a Creative Commons Attribution 4.0 International License, which permits use, sharing, adaptation, distribution and reproduction in any medium or format, as long as you give appropriate credit to the original author(s) and the source, provide a link to the Creative Commons licence, and indicate if changes were made. The images or other third party material in this article are included in the article's Creative Commons licence, unless indicated otherwise in a credit line to the material. If material is not included in the article's Creative Commons licence and your intended use is not permitted by statutory regulation or exceeds the permitted use, you will need to obtain permission directly from the copyright holder. To view a copy of this licence, visit http://creativecommons.org/licenses/by/4.0/. The Creative Commons Public Domain Dedication waiver (http://creativecommons.org/publicdomain/zero/1.0/) applies to the data made available in this article, unless otherwise stated in a credit line to the data. 
re-infections [1]. Residuals of destroyed asexual parasites, and live or destroyed gametocytes, are possible sources of post-treatment Plasmodium DNA in patients cured of their malaria infection. Gametocytes are sexual forms of malaria parasites responsible for transmission between humans after completion of their cycle in mosquitoes. They cause no clinical symptoms in the human host. In Plasmodium falciparum, immature gametocytes sequester in internal host organs, particularly in the bone marrow, and undergo five morphological development stages in the course of 7-12 days, hence only mature gametocytes circulate in the blood until they die of age $[2,3]$. It has been estimated from mathematical modelling that P. falciparum gametocyte carriage may persist for up to 55 days after treatment [4]. Primaquine (PQ) is the only drug effective against mature gametocytes, and is added to artemisinins in routine treatment of $P$. falciparum in many malaria-endemic areas to prevent transmission [5, 6]. Artemisinin also has some effect on gametocyte carriage duration, through the effect on immature gametocytes and rapid killing of asexual parasites [5]. Less is known about Plasmodium vivax gametocytes. It seems that immature $P$. vivax gametocytes sequester mainly in the bone marrow, similar to P. falciparum [7]. However they mature much faster than $P$. falciparum gametocytes, they are commonly present before symptoms and before parasite detection by microscopy, and live only for up to three days $[2,8]$.

Several malaria PCR methods have been introduced applying different amplification targets on the parasite genome. The real-time PCR targeting var gene acidic terminal sequence (varATS) on the chromosomal genome, and cytochrome $b$ (cytb) on the mitochondrial genome, are among the most sensitive ones [9]. The varATS gene exists in 59 copies for each parasite nucleus [10], while the number of copies of the $c y t b$ gene varies depending on parasite stage; ring-stage parasites have about 20 copies, and gametocytes about 160 copies [11, 12]. Gametocyte-specific mRNA transcripts can be detected by reverse transcript (RT)-PCR methods [13, 14].

The objective of this clinical observational study was to describe the presence of positive PCR for P. falciparum and $P$. vivax in follow-up samples post-treatment from returned travellers, and the proportion of positive PCR due to gametocytes, applying PCR methods detecting Plasmodium DNA and gametocyte-specific mRNA.

\section{Methods}

\section{Patient material}

Blood samples from adult patients, diagnosed with malaria by microscopy and/or rapid diagnostic test at Haukeland University Hospital, Bergen, were collected in the period 2013-2015. Blood samples were collected during hospitalization and at routine follow-up in the outpatient clinic at 11-54 days after treatment. Clinical information and results from routine microscopy was collected retrospectively from patient records.

\section{PCR methods}

DNA was extracted from EDTA whole blood applying QIAamp DNA Blood Mini Kit (Qiagen, Hilden, Germany), while mRNA was collected and extracted applying PAXgene Blood RNA Tubes and Kit (PreAnalytiX, Hombrechtikon, Switzerland), according to the manufacturer's instructions.

All the DNA samples $(\mathrm{N}=25)$ were analysed with a genus-specific cytb real-time SYBR PCR, and the $P$. falciparum DNA samples $(\mathrm{N}=22)$ were also analysed with a falciparum-specific varATS real-time TaqMan PCR, following previously published methods $[9,10]$. All the mRNA samples $(\mathrm{N}=18)$ were analysed both with a genus-specific $18 \mathrm{~S}$ rRNA RT-PCR (detecting mRNA transcripts produced by all parasite stages), and a gametocyte-specific Pfs25 (P. falciparum)/Pvs25 (P. vivax) RT-PCR detecting female gametocytes, following previously published methods [14]. In addition, quantitative analysis was performed for the $c y t b$ real-time PCR and Pfs25/Pvs25 RT-PCR runs by applying tenfold dilution series of customized plasmids designed with EcoRI linearized q-PCR template and a pUCminusMCS vector backbone (OriGene Technologies, Rockville, MD, USA). All samples were run in triplicates, and a positive result was defined as at least two out of three detections.

\section{Results}

The PCR results applying DNA and mRNA template, including mean $C_{t}$ values as well as quantitative numbers, are presented in Table 1. Genus DNA cytb PCR was positive up to 49 days after effective treatment, and $18 \mathrm{~S}$ rRNA transcripts from active $P$. falciparum parasites were detectable for at least 11 days. Microscopy and/or PCR detected gametocytes in 67\% (8/12) patients, but gametocyte-specific mRNA was detected at latest only two days after treatment. Late detection of $P$. vivax was not found by any of the PCR methods.

All patients were asymptomatic and had negative microscopy at outpatient follow-up visits. The association between positive PCR, microscopy findings and clinical characteristics is presented in Table 2 . Six patients with $P$. falciparum were treated with artesunate intravenously, followed by a full oral course of artemether-lumefantrine (AL) or atovaquone-proguanil (AP), while two received only $\mathrm{AL}$ and one only AP. All $P$. vivax patients, and no P. falciparum patients, received primaquine. Among the six patients with late P. falciparum positive PCR (day 11-49), four had high parasitaemia $(6-30 \%)$ while two had parasitaemia $<2 \%$ at 
Table 1 Plasmodium DNA and gametocyte-specific mRNA detections among malaria patients after treatment $(\mathrm{N}=13)$

\begin{tabular}{|c|c|c|c|c|c|c|c|c|c|}
\hline Patient & Species & $\begin{array}{l}\text { No days } \\
\text { since treatment }\end{array}$ & $\begin{array}{l}\text { Microscopy } \\
\text { (parasite \%) }\end{array}$ & $\begin{array}{l}\text { Genus DNA } \\
\text { Cytb PCR }\left(C_{t}\right)\end{array}$ & No copies/rxn & $\begin{array}{l}\text { P.f DNA } \\
\text { VarATS PCR } \\
\left(C_{t}\right)\end{array}$ & $\begin{array}{l}\text { Genus } 18 S \\
\text { mRNA PCR } \\
\left(C_{t}\right)\end{array}$ & $\begin{array}{l}\text { Pfs25/Pvs25 } \\
\text { mRNA PCR } \\
\left(C_{t}\right)\end{array}$ & No. copies/rxn \\
\hline \multirow[t]{2}{*}{ No. 1} & $P . f+P . m$ & 0 & Pos (2) & Pos (24) & $1.1 \times 10^{3}$ & Pos (26) & & & \\
\hline & & 1 & Pos (1) & Pos (25) & $4.3 \times 10^{2}$ & Pos (28) & Pos (17) & Pos (29) & $3.2 \times 10^{3}$ \\
\hline \multirow[t]{2}{*}{ No. 2} & P.f & 0 & Pos (4) & Pos (18) & $5.7 \times 10^{5}$ & Pos (19) & & & \\
\hline & & 1 & Pos (4) & Pos (21) & $7.0 \times 10^{5}$ & Pos (22) & Pos (12) & Pos (34) & 95 \\
\hline \multirow[t]{4}{*}{ No. 3} & P.f & 0 & Pos (12) & & & & & & \\
\hline & & 1 & Neg & Pos (22) & $3.7 \times 10^{4}$ & Pos (26) & & & \\
\hline & & 2 & Neg & $\operatorname{Pos}(23)$ & $1.5 \times 10^{4}$ & Pos (29) & & & \\
\hline & & 11 & Neg & Pos (30) & 200 & Pos (35) & Pos (25) & Neg & \\
\hline \multirow[t]{2}{*}{ No. 4} & P.f & 0 & $\operatorname{Pos}(<1)^{*}$ & & & & & & \\
\hline & & 31 & Neg & Neg & & Neg & Neg & & \\
\hline \multirow[t]{2}{*}{ No. 5} & P.f & 0 & $\operatorname{Pos}(<1)$ & & & & & & \\
\hline & & 32 & Neg & Pos (37) & 2 & Neg & Neg & & \\
\hline \multirow[t]{3}{*}{ No. 6} & P.f & 0 & $\operatorname{Pos}(2)$ & Pos (19) & $3.9 \times 10^{5}$ & Pos (20) & & & \\
\hline & & 1 & $\operatorname{Pos}(<0.5)$ & Pos (24) & $7.7 \times 10^{3}$ & Pos (27) & Pos (17) & Pos (31) & 420 \\
\hline & & 37 & Neg & Pos (39) & 1 & Neg & Neg & & \\
\hline \multirow[t]{4}{*}{ No. 7} & P.f & 0 & Pos (10) & Pos (15) & $4.0 \times 10^{6}$ & Pos (16) & & & \\
\hline & & 4 & Neg & Pos (25) & $6.3 \times 10^{3}$ & Pos (29) & Pos (23) & Neg & \\
\hline & & 11 & Neg & Pos (29) & 400 & Pos (35) & Pos (24) & Neg & \\
\hline & & 39 & Neg & Neg & & Neg & Neg & Neg & \\
\hline \multirow[t]{3}{*}{ No. 8} & P.f & 0 & Pos (30) & Pos (16) & $1.8 \times 10^{6}$ & Pos (18) & & & \\
\hline & & 1 & Pos (6) & $\operatorname{Pos}(16)$ & $3.0 \times 10^{6}$ & Pos (17) & $\operatorname{Pos}(7)$ & Pos (29) & $2.2 \times 10^{3}$ \\
\hline & & 45 & Neg & Pos (34) & 16 & Neg & Neg & Neg & \\
\hline \multirow[t]{2}{*}{ No. 9} & P.f & 0 & $\operatorname{Pos}(6)^{*}$ & & & & & & \\
\hline & & 49 & Neg & Pos (34) & 11 & Pos (36) & Neg & Neg & \\
\hline \multirow[t]{2}{*}{ No.10 } & P.V & 0 & Pos (0.5) & & & & & & \\
\hline & & 2 & Pos $^{*}$ & & & & $\operatorname{Pos}(7)$ & Pos (17) & $9.6 \times 10^{6}$ \\
\hline \multirow[t]{2}{*}{ No. 11} & P.V & 0 & $\operatorname{Pos}(0.5)^{\mathrm{a}}$ & & & & & & \\
\hline & & 6 & Neg & Pos (39) & 1 & & Neg & Neg & \\
\hline \multirow[t]{2}{*}{ No. 12} & P.V & 0 & Pos & Pos (22) & $4.8 \times 10^{4}$ & & & & \\
\hline & & 23 & Neg & Neg & & & Neg & Neg & \\
\hline \multirow[t]{2}{*}{ No. 13} & P.V & 0 & Pos & & & & & & \\
\hline & & 54 & Neg & Neg & & Neg & Neg & Neg & \\
\hline
\end{tabular}

rxn reaction

${ }^{a}$ Gametocytes seen by microscopy

admittance, and three had gametocytes detected. A clear association between low/high $P$. falciparum parasitaemia and duration of positive PCR detections was not found. One patient with late positive PCR was of Norwegian origin, while five were from sub-Saharan Africa and had lived from 10-46 years in Norway. Two of the patients with late positive PCR were immunodeficient with HIV or sickle cell disease.

\section{Discussion}

In this observational study, DNA-based PCR was positive up to seven weeks after effective malaria treatment. No patients had clinical signs of recrudescence, and there was no risk of re-infection. This is in line with a previous report that found positive malaria PCR after six weeks in a group of returned travellers in Sweden [1]. Positive PCR for weeks after effective treatment of infections is a 
Table 2 PCR results associated with microscopy findings and clinical characteristics

\begin{tabular}{|c|c|c|c|c|c|c|c|c|}
\hline Patient & Species & $\begin{array}{l}\text { No. days } \\
\text { since treatment }\end{array}$ & $\begin{array}{l}\text { Microscopy } \\
\text { (parasite\%) }\end{array}$ & PCR & $\begin{array}{l}\text { Fever duration } \\
\text { before treatment } \\
\text { (days) }\end{array}$ & Treatment & $\begin{array}{l}\text { Origin/years } \\
\text { out of endemic } \\
\text { area }\end{array}$ & Comorbidity \\
\hline \multirow[t]{2}{*}{ No. 1} & $P . f+P . m$ & 0 & Pos (2) & Pos & 35 & $A L$ & SSA/1 & HIV \\
\hline & & 1 & Pos (1) & $\operatorname{Pos}^{b, c}$ & & & & \\
\hline \multirow[t]{2}{*}{ No. 2} & P.f & 0 & Pos (4) & Pos & 2 & $A, A L$ & $\mathrm{SSA} / 8$ & HIV \\
\hline & & 1 & Pos (4) & $\operatorname{Pos}^{b, c}$ & & & & \\
\hline \multirow[t]{4}{*}{ No. 3} & P.f & 0 & Pos (12) & & 3 & $A, A P$ & Norway & \\
\hline & & 1 & Neg & Pos & & & & \\
\hline & & 2 & Neg & Pos & & & & \\
\hline & & 11 & Neg & $\operatorname{Pos}^{b}$ & & & & \\
\hline \multirow[t]{2}{*}{ No. 4} & P.f & 0 & $\operatorname{Pos}(<1)^{\mathrm{a}}$ & & 38 & AP & SSA/10 & \\
\hline & & 31 & Neg & Neg & & & & \\
\hline \multirow[t]{2}{*}{ No. 5} & P.f & 0 & $\operatorname{Pos}(<1)$ & & 7 & $\mathrm{AL}$ & $\mathrm{SSA} / 46$ & \\
\hline & & 32 & Neg & Pos & & & & \\
\hline \multirow[t]{3}{*}{ No. 6} & P.f & 0 & Pos (2) & Pos & 9 & $\mathrm{Q}, \mathrm{A}, \mathrm{AL}$ & $\mathrm{SSA} / 21$ & \\
\hline & & 1 & $\operatorname{Pos}(<0.5)$ & $\operatorname{Pos}^{b, c}$ & & & & \\
\hline & & 37 & Neg & Pos & & & & \\
\hline \multirow[t]{4}{*}{ No. 7} & P.f & 0 & Pos (10) & Pos & 21 & $A, A L$ & SSA/10 & HIV \\
\hline & & 4 & Neg & Pos & & & & \\
\hline & & 11 & Neg & Pos & & & & \\
\hline & & 39 & Neg & Neg & & & & \\
\hline \multirow[t]{3}{*}{ No. 8} & P.f & 0 & Pos (30) & Pos & 3 & $\mathrm{~A}$, & Norway & \\
\hline & & 1 & Pos (6) & $\operatorname{Pos}^{b, c}$ & & Erythrocyte & & \\
\hline & & 45 & Neg & Pos & & apheresis, AL & & \\
\hline \multirow[t]{2}{*}{ No. 9} & $P . f$ & 0 & $\operatorname{Pos}(6)^{a}$ & & 13 & $A, A P, A L$ & SSA/17 & Sickle cell disease \\
\hline & & 49 & Neg & Pos & & & & \\
\hline \multirow[t]{2}{*}{ No.10 } & P.V & 0 & Pos (0.5) & & 10 & $A P, P$ & SEA/30 & \\
\hline & & 2 & $\operatorname{Pos}^{\mathrm{a}}$ & $\operatorname{Pos}^{b, c}$ & & & & \\
\hline \multirow[t]{2}{*}{ No. 11} & P.V & 0 & $\operatorname{Pos}(0.5)^{\mathrm{a}}$ & & Not known & $A P, P$ & SSA & \\
\hline & & 6 & Neg & Pos & & & & \\
\hline \multirow[t]{2}{*}{ No. 12} & P.V & 0 & Pos & Pos & 2 & $A, A P, P$ & Norway & \\
\hline & & 23 & Neg & Neg & & & & \\
\hline \multirow[t]{2}{*}{ No. 13} & P.V & 0 & Pos & & 6 & $C, P$ & Norway & \\
\hline & & 54 & Neg & Neg & & & & \\
\hline
\end{tabular}

$A L$ artemether-lumefantrine, $A$ artesunate IV (intravenous), $P A$ atovaquone-proguanil, $Q$ quinine IV, $C$ chloroquine, $P$ primaquine, HIV human immunodeficiency virus, SSA sub-Saharan Africa, SEA Southeast Asia

a Gametocytes seen by microscopy

b Detection of $18 \mathrm{~S}$ mRNA transcripts (Produced by all parasite stages)

c Detection of gametocyte-specific mRNA

common phenomenon; a study investigating detectable DNA after treatment of Chlamydia trachomatis, Neisseria gonorrhoeae and Trichomonas vaginalis infections, reported that PCR could be positive up to three weeks post-treatment [15].

Molecular studies have shown that most individuals with asexual parasites also have sub-microscopic gametocyte carriage [16]. In general, the level of circulating gametocytes is low, about 5\% compared to other parasite-stages. Gametocytes were detected by microscopy and/or RT-PCR in $67 \%(8 / 12)$ of the patients in the present study. However, gametocyte-specific mRNA was not detected in the late follow-up samples, similar to that reported by Vafa Homann et al. in Sweden [1], which might indicate that the detection of Plasmodium DNA origin from residuals of destroyed parasites. The phagocytic system has the potential to remove up to $40-80 \%$ of malaria infected red blood cells (RBCs) in a few days, but due to sequestration of infected RBCs in organs, the time of complete clearance of parasite residuals is unknown 
[17]. Drug treatment may also have contributed to clear gametocytes. All the P. falciparum patients were treated with artemisinin, which has some gametocidal effect, and all $P$. vivax patients were treated with $P Q$, which has a strong gametocidal effect. In a study from Kenya and Tanzania estimating gametocyte carriage following treatment with non-artemisinin drugs, artemisinin, and artemisinin in combination with $\mathrm{PQ}$, duration of gametocytaemia was 55, 13 and 6 days, respectively [4].

Collection, handling and analysis of mRNA is challenging $[18,19]$, and due to the instability of mRNA versus DNA, difference in sensitivity between the methods can be a factor that may underestimate late gametocytaemia in this study. A study investigating a similar gametocyte-specific $P f s 25$ RT-PCR, reported that in dilution series down to 0.05 and 0.01 gametocytes $/ \mu$, the lowest density samples were often negative [20]. In the present study, the quantitative values detected by $c y t b$ DNA PCR in samples $>30$ days after treatment correspond to $\leq 0.05$ gametocytes $/ \mu \mathrm{l}$, so potentially these could have gametocytaemia below detection level of mRNA RT-PCR.

In the study from Kenya and Tanzania investigating gametocytaemia, a nucleic acid sequence based amplification (NASBA) method detecting $P f s 25$ mRNA was applied, a method slightly more sensitive than $P f s 25$ RTPCR; gametocytes were found in $5-78 \%$ of the samples at day 14 , and $12-48 \%$ at day 28 [4]. However, compared to returned travellers in the present study, patients in malaria-endemic areas may have a higher level of gametocyte carriage post-treatment due to reasons such as late admission and delayed treatment, use of less effective drugs, self-medication with sub-optimal regimes, re-infection, or gametocyte carriage that originate from previous undetected low-density infections.

Looking only at the two DNA-based PCR assays, the cytb PCR detected more late follow-up samples than varATS PCR. Hypothetically this could be explained by detection of gametocytes, since the $c y t b$ method detect mitochondrial DNA present in large amounts in gametocytes. In regard to copy number, the cytb PCR is about 2.5 times more sensitive in detecting gametocytes than varATS PCR, while the varATS PCR is about three times more sensitive than cytb PCR in detecting asexual parasites. In a study applying field samples from Tanzania, the sensitivity in detecting low level parasitaemia by different real-time malaria PCR methods where compared, and the varATS PCR was then found to be more sensitive than $c y t b$ PCR [9].

Two samples 11 days after treatment were positive by $18 \mathrm{~S}$ rRNA RT-PCR (mRNA), but not by the gametocyte specific Pfs25 RT-PCR, indicating that possible live asexual parasites circulated in the bloodstream in low densities at this point. Although, negative gametocyte specific $P f s 25$ RT-PCR due to lower sensitivity could also be possible. The quantitative levels by the DNA PCR after 11 days correspond to $<5$ parasites/ $\mu$ l. Post-treatment asexual parasites that survive until they are cleared by the immune system continue to produce gametocytes, which also could support the reported phenomenon of gametocyte carriage for several weeks after treatment [4].

For the $P$. vivax samples, a high level of mRNA from gametocytes was detected by the Pvs 25 RT-PCR at day 2 after treatment, but both mRNA assays were negative for the late follow-up samples. The $c y t b$ DNA PCR was positive at day 6 , though with parasitaemia as low as 0.025 parasites $/ \mu$ l. These results are consistent with the short duration of gametocytaemia in $P$. vivax [2]. The results for $P$. vivax also support that persistent positive $P$. falciparum PCR could be caused by gametocytes; if positive P. falciparum PCR was caused only by DNA residuals, it would be expected that also $P$. vivax was PCR positive days/weeks after treatment similar in P. falciparum infections. An association between high $P$. falciparum parasitaemia and persistent PCR would intuitively be expected. However, similar to that reported by Vafa Homann et al. among Swedish travellers [1], no clear association between low/high level of parasitaemia and persistent positive PCR was identified in the present study.

\section{Conclusions}

DNA-based PCR can be positive up to at least seven weeks after curative malaria treatment, potentially leading to over-diagnose of recrudescence and re-infections. Based on the observations in this study, it is unclear if the DNA origin from residuals of destroyed parasites or live gametocytes. Further studies of both $P$. vivax and $P$. falciparum are needed, since different gametocytaemia biology and treatment-regimes have the potential to give informative answers.

\section{Abbreviations}

PCR: Polymerase chain reaction; PQ: Primaquine (PQ); varATS: var Gene acidic terminal sequence; cytb: Cytochrome b; RT: Reverse transcript; AL: Artemetherlumefantrin; AP: Atovaquone-proguanil; RBCs: Red blood cells.

\section{Acknowledgements \\ Not applicable.}

\section{Authors' contributions}

CGH performed the laboratory analyses, and wrote the first draft of the manuscript. KM recruited patients for the sample collection, recorded and analysed clinical data, and supervised the study. Both authors contributed to the planning of the study, revision of the manuscript. Both authors read and approved the final manuscript.

\section{Funding}

This work was funded by Norwegian National Advisory Unit on Tropical Infectious Diseases, Department of Medicine, Haukeland University Hospital, Bergen, Norway. 


\section{Availability of data and material}

The datasets used during the current study are available from the corresponding author on reasonable request.

\section{Ethics approval and consent to participate}

The study was approved by the regional ethics committee in Norway (2017/47/REK vest), and the patients gave written informed consents to participate. Treatment and monitoring of patients was done according to clinical routine practice.

\section{Consent for publication}

Not applicable.

\section{Competing interests}

The authors declare that they have no competing interests.

\section{Author details}

${ }^{1}$ Norwegian National Advisory Unit On Tropical Infectious Diseases, Unit for Infectious Diseases, Department of Medicine, Haukeland University Hospital, Bergen, Norway. ${ }^{2}$ Department of Clinical Science, University of Bergen, Bergen, Norway.

Received: 27 May 2020 Accepted: 10 August 2020

Published online: 19 August 2020

\section{References}

1. Vafa Homann M, Emami SN, Yman V, Stenstrom C, Sonden K, Ramstrom $\mathrm{H}$, et al. Detection of malaria parasites after treatment in travelers: a 12-months longitudinal study and statistical modelling analysis. EBioMed. 2017;25:66-72.

2. Bousema T, Drakeley C. Epidemiology and infectivity of Plasmodium falciparum and Plasmodium vivax gametocytes in relation to malaria control and elimination. Clin Microbiol Rev. 2011:24:377-410.

3. Gardiner DL, Trenholme KR. Plasmodium falciparum gametocytes: playing hide and seek. Ann Transl Med. 2015:3:45.

4. Bousema T, Okell L, Shekalaghe S, Griffin JT, Omar S, Sawa P, et al. Revisiting the circulation time of Plasmodium falciparum gametocytes: molecular detection methods to estimate the duration of gametocyte carriage and the effect of gametocytocidal drugs. Malar J. 2010;9:136.

5. WHO. Guidelines for the treatment of malaria. 3rd ed. Geneva: World Health Organization; 2015.

6. Shekalaghe S, Drakeley C, Gosling R, Ndaro A, van Meegeren M, Enevold A, et al. Primaquine clears submicroscopic Plasmodium falciparum gametocytes that persist after treatment with sulphadoxine-pyrimethamine and artesunate. PLOS ONE. 2007;2:e1023.

7. Obaldia 3rd N, Meibalan E, Sa JM, Ma S, Clark MA, Mejia P, et al. Bone marrow is a major parasite reservoir in Plasmodium vivax infection. mBio. 2018:9:e00625-18.
8. Meibalan E, Marti M. Biology of malaria transmission. Cold Spring Harb Perspect Med. 2017;7:a025452.

9. Haanshuus CG, Morch K, Blomberg B, Strom GEA, Langeland N, Hanevik $\mathrm{K}$, et al. Assessment of malaria real-time PCR methods and application with focus on low-level parasitaemia. PLoS ONE. 2019;14:e0218982.

10. Hofmann N, Mwingira F, Shekalaghe S, Robinson LJ, Mueller I, Felger I. Ultra-sensitive detection of Plasmodium falciparum by amplification of multi-copy subtelomeric targets. PLoS Med. 2015;12:e1001788.

11. Preiser PR, Wilson RJ, Moore PW, McCready S, Hajibagheri MA, Blight KJ, et al. Recombination associated with replication of malarial mitochondrial DNA. EMBO J. 1996;15:684-93.

12. Krungkrai J. The multiple roles of the mitochondrion of the malarial parasite. Parasitology. 2004;129:511-24.

13. Babiker HA, Abdel-Wahab A, Ahmed S, Suleiman S, Ranford-Cartwright L, Carter R, et al. Detection of low level Plasmodium falciparum gametocytes using reverse transcriptase polymerase chain reaction. Mol Biochem Parasitol. 1999;99:143-8.

14. Wampfler R, Mwingira F, Javati S, Robinson L, Betuela I, Siba P, et al. Strategies for detection of Plasmodium species gametocytes. PLOS ONE. 2013;8:e76316

15. Williams JA, Ofner S, Batteiger BE, Fortenberry JD, Van Der Pol B. Duration of polymerase chain reaction-detectable DNA after treatment of Chlamydia trachomatis, Neisseria gonorrhoeae, and Trichomonas vaginalis infections in women. Sex Transm Dis. 2014;41:215-9.

16. Schneider P, Bousema JT, Gouagna LC, Otieno S, van de Vegte-Bolmer M, Omar SA, et al. Submicroscopic Plasmodium falciparum gametocyte densities frequently result in mosquito infection. Am J Trop Med Hyg. 2007;76:470-4.

17. Ho M, Webster HK. Immunology of human malaria. A cellular perspective Parasite Immunol. 1989;11:105-16.

18. Kagedal B, Lindqvist M, Farneback M, Lenner L, Peterson C. Failure of the PAXgene blood RNA system to maintain mRNA stability in whole blood. Clin Chem Lab Med. 2005:43:1190-2.

19. Meyer A, Paroni F, Gunther K, Dharmadhikari G, Ahrens W, Kelm S, et al. Evaluation of existing methods for human blood mRNA isolation and analysis for large studies. PLOS ONE. 2016;11:e0161778.

20. Pett H, Goncalves BP, Dicko A, Nebie I, Tiono AB, Lanke K, et al. Comparison of molecular quantification of Plasmodium falciparum gametocytes by Pfs 25 qRT-PCR and QT-NASBA in relation to mosquito infectivity. Malar J. 2016;15:539.

\section{Publisher's Note}

Springer Nature remains neutral with regard to jurisdictional claims in published maps and institutional affiliations.

Ready to submit your research? Choose BMC and benefit from

- fast, convenient online submission

- thorough peer review by experienced researchers in your field

- rapid publication on acceptance

- support for research data, including large and complex data types

- gold Open Access which fosters wider collaboration and increased citations

- maximum visibility for your research: over 100M website views per year

At BMC, research is always in progress.

Learn more biomedcentral.com/submissions 